\title{
Sosialisasi Program Latihan Motor Ablity Kepada Asisten Pelatih Dojo Lembaga Karate-Do Indonesia Se-Kecamatan Koto Tangah
}

\author{
Arie Asnaldi ${ }^{1}$, Kibadra ${ }^{2}$ \\ Jurusan Pendidikan Olahraga, Fakultas Ilmu Keolahragaan, Universitas Negeri Padang \\ Email: asnaldi@fik.unp.ac.id ${ }^{1}$, kibadra@ fik.unp.ac.id ${ }^{2}$
}

\begin{abstract}
The role of a Dojo trainer in directing karateka to be able to achieve the things mentioned above, the City of Padang has many Dojo including the Dojo Angkasa Lanud Padang. Dojo in the general sense is a training ground. According to Wahid (2007: 8) Dojo which means "a place to study" in Japanese in the past refers to the meaning of "hall to meditate in the temple".

Padang Dojo Angkasa Lanud is one of the Dojo Lemkari (Indonesian Karate-DO Institute) which has a Karate shutdown in Padang City, the karateka dojo consists of students from Angkasa Lanud Padang Middle School and the general public. Karateka at the Lemkari Angkasa Lanud Dojo Padang has a variety of achievements where in the past it had had quite a proud achievement that karateka performed in the Kata and kumite categories.

Keywords: Karate, Lemkari, Motor Ability, Words, Kumite

Abstrak

Peran sebuah pelatih Dojo dalam mengarahkan para karateka untuk dapat mencapai hal-hal yang tersebut di atas, Kota Padang memiliki banyak Dojo diantaranya adalah Dojo Angkasa Lanud Padang. Dojo dalam artian umum adalah tempat latihan. Menurut Wahid (2007:8) Dojo yang berarti "tempat untuk mempelajari" dalam bahasa jepang pada zaman lampau lebih mengacu pada arti "aula untuk bermeditasi dalam kuil".

Dojo Angkasa Lanud Padang adalah salah satu Dojo Lemkari (Lembaga Karate-DO Indonesia) yang beraliran shutokan Karate yang ada di Kota Padang, karateka yang dojo ini terdiri dari siswa-siswi SMP Angkasa Lanud Padang dan juga masyarakat umum. Karateka pada Dojo Lemkari Angkasa Lanud Padang memiliki berbagai macam prestasi dimana dahulu sempat memiliki prestasi yang cukup membanggakan karateka yang beprestasi pada kategori Kata dan kumite.

Kata Kunci: Karete, Lemkari, Motor Ability, Kata, Kumite
\end{abstract}

\section{ANALISIS SITUASI}

Setiap pelatih memberikan program latih fisik kepada atlitnya tetapi tidak dapat mengetahui bagaimana peningkatan kemampuan fisik atlit tersebut. Untuk mengetahui kemampuan fisik atlit tersebut maka setiap pelatih seharusnya dapat melakukan tes dan pengkuran fisik atlit. Dan untuk mengetahui peningkatannya maka pelatih dapat melakukan evaluasinya.

Tes,Pengukuran,dan Evaluasi merupakan bagian yang tak terpisahkan dalam berbagai kegiatan manusia, demikian pula halnya dalam kegiatan pengajaran dan pelatihan olahraga. Karena dengan melaksanakan ketiga hal tersebut kita dapat mengetahui perkembangan dan kekurangan, sehingga akhirnya dapat membuat suatu keputusan yang tepat. Pengajaran dan

67 | Sosialisasi Program Latihan Motor Ablity

Arie Asnaldi ${ }^{1}$, Kibadra ${ }^{2}$ 
JURNAL BERKARYA PENGABDIAN PADA MASYALTHKAS

Volume 1, No.1, 2019

ISSN-

(Print) I

Open Access | http:jba.ppj.unpracild

pelatihan olahraga merupakan sebuah proses yang dinamis, pengajar/pelatih dan pembina menghadapi berbagai permasalahan yang membutuhkan pemecahan. Semakin teliti informasi yang diperoleh (melalui tes dan pengukuran) akan semakin baik keputusan yang diambil.

Dari beberapa hasil temuan di atas secara umum pengetahuan dan kemampuan pelatih terhadap tes pengkuran dan evaluasi kemampuan fisik atlit masih kurang baik. Selain itu, pelatih juga kurang melakukan evaluasi terhadap fisik atlitnnya sendiri. Melihat kondisi yang demikian perlu dilakukan pembinaan tentang pemahaman dan pelatihan terhadap tes pengukuran dan evaluasi kondisi fisik bagi pelatih.

Kemampuan gerak dalam proses, penulis melihat secara realitas masih banyak karateka melakukan gerak kihon masih dalam keraguan sehingga gerak yang ditampil telihat kaku dan terhambat, karateka hanya memperhatikan gerak yang diperaga oleh pelatih dan melakukan gerakan tersebut sesuai instruksi. Setalah berlatih gerakan-gerakan dasar (kihon) barulah karateka diberikan pengenal kata. (Asnaldi:2019)

Untuk mewujudkan harapan tersebut, lembaga pengabdian kepada masyarakat Universitas Negeri Padang (LPM-UNP) melalui tim staf pengajarnya yang telah melakukan kerja sama dengan Dojo Angkasa Lanud salah satu Dojo yang ada di Kecamatan Koto Tangah Kota Padang, rencananya akan dilakukan penyuluhan dan pelatihan pelaksanaan tes pengukuran dan evaluasi motor ability bagi pelatih-pelatih Dojo yang di Kecamatan Koto Tangah Kota Padang.

\section{SOLUSI DAN TARGET}

Berdasarkan permasalahan yang dikemukakan pada bagian terdahulu, maka jenis luaran yang ingin dicapai adalah:

1. Karateka Dojo Angkasa Lanud Padang dapat merasakan, mencoba penerapan materi keterampilan dan kemampuan motorik dan gerakan yang disiapkan sebelumnya oleh Tim Pelaksana Pelatihan dari UNP.

2. Masih kurangnya penyuluhan-penyuluhan yang dilakukan oleh instansi terkait dalam pemberian pemahaman tentang tes pengukuran dan evaluasi keterampilan dan kemampuan motorik dan gerakan bagi karateka.

\section{8 | Sosialisasi Program Latihan Motor Ablity}

Arie Asnaldi ${ }^{1}$, Kibadra ${ }^{2}$ 
JURNAL BERKARYA PENGABDIAN PADA MASYALTHKAS

Volume 1, No.1, 2019

ISSN-

(Print) I

Open Access / http:jba.ppj.unp.acild

3. Masih kurangnya pengetahuan pelatih tentang pelaksanaan tes pengukuran dan evaluasi keterampilan dan kemampuan motorik dan gerakan.

4. Diharapkan dengan adanya pelatihan ini, minimal motivasi karateka untuk melakukan latihan akan lebih bergairah.

\section{METODE PELAKSANAAN}

Perkembangan olahraga karate di Sumatera Barat secara umum dapat dikatakan sangat mengembirakan namun demikian untuk pengetahuan dan pemaham pelatih dapat dikatakan sangat lambat sekali perkembangannya. Oleh sebab itu salah satu langkah yang digunakan untuk lebih berkembangnya karate, diperlukan kerjasama antara Penguruan Tinggi dengan Pengurus Daerah, Pengurus Ranting dan Pengurus Dojo.

\section{Tempat dan Waktu.}

Dojo Angkasa Lanud Padang.

\section{Khalayak Sasaran.}

Perkembangan olahraga karate di Sumatera Barat secara umum dapat dikatakan sangat mengembirakan namun demikian untuk pengetahuan dan pemaham pelatih dapat dikatakan sangat lambat sekali perkembangannya. Oleh sebab itu salah satu langkah yang digunakan untuk lebih berkembangnya karate, diperlukan kerjasama antara Penguruan Tinggi dengan Pengurus Daerah, Pengurus Ranting dan Pengurus Dojo.

\section{Metode Pengabdian}

Peserta dan fasilitator pelatihan (pelatih) merupakan sumber belajar yang bersama-sama menggali pengalaman-pengalaman. Secara terstruktur pengalaman tersebut diungkapkan, dianalisa, dan kemudian disintesiskan bersama untuk mendapatkan prinsip-prinsip baru yang untuk diterapkan Setiap proses penyajian materi melalui tahapan.

\section{Indikator Keberhasilan.}

\section{a. Tahap mengalami (Exeriencing)}

Pada tahap awal ini, fasilitator mengajak peserta meninjau kembali pengalamanpengalaman yang sudah dimiliki peserta atau contoh-contoh dari keadaan sehari-hari yang terkait dengan materi, misalnya keadaan pengurus cabang yang masih belum mempunyai atlit yang

\section{9 | Sosialisasi Program Latihan Motor Ablity}

Arie Asnaldi ${ }^{1}$, Kibadra ${ }^{2}$ 
JURNAL BERKARYA PENGABDIAN PADA MASYALTAKAJ

Volume 1, No.1, 2019

ISSN-

(Print) I

(Online)

Open Access / http:jba.ppj.unpracild

handal dalam olahraga dayung. Pengalaman tersebut dijadikan bahan kajian. Apabila pengalaman tidak dapat dicari maka fasilitator mengajak peserta melakukan tindakan-tindakan yang sesuai dengan materi yang hendak dibahas bersama. Jadi pengalaman ini dapat berupa pengalaman yang sudah dimiliki peserta atau pengalaman yang sengaja diciptakan dalam kelas.

\section{b. Tahap Mengolah (Processing)}

Tahap ini ada dua langkah utama yaitu:

1. Mengungkapkan Keadaan atau pengalaman itu diungkapkan kembali oleh peserta dengan menyatakan,apa yang terjadi; misalnya apa yang terpikirkan, apa yang dirasakan, Peserta maupun pelatih menceritakan kembali keadaan/ pengalaman tersebut.

2. Menganalisa, Dalam tahapan ini, dibahas mengapa terjadi, bagaimana terjadinya. Mencari kaitan apakah hal-hal tersebut dengan pengalaman-pengalaman lainnya. Peserta maupun pelatih dapat memberikan contoh-contoh pengalaman sejenis sehingga membantu memperjelas masalah yang sedang dikaji. Merumuskan apa yang dapat dipelajari dan apa makna dari semua pengalaman-pengalaman tadi.

\section{c. Tahap menyimpulkan (Generalizing)}

Dari keseluruhan pengalaman yang dianalisa tadi dirumuskan; apa yang berlaku secara umum (generalisasi) sehingga, dan apakah dapat menjadi prinsip-prinsip teoritis sehingga dapat menjadi kesimpulan.

\section{d. Tahap Menerapkan (Applying)}

Prinsip-prinsip yang disimpulkan dari pengalaman tersbut menjadi ajaran atau penemuan baru. Sehingga menjadi bahan yang sapat dipergunakan untuk mengkaji pengalaman baru berupa pengetahuan atau pemahaman, sikap-sikap posotif maupun ketrampilan yang meningkat.

Pemberian Soft File dalam bentuk Video, slide dan Piagam. Dengan metode community based diharapkan setiap pelatih-pelatih di kecamatan koto tangah dapat memperkenalkan kepada karatekanya.

\section{Metode Evaluasi.}

Kegiatan ini berlangsung selama tiga 1 (satu) minggu.Tempat pelaksanaanya di tempat Dojo Angkasa Lanud Padang di kecamatan Koto Tangah. Adapun metode yang akan dipakai adalah sebagai berikut:

\section{0 | Sosialisasi Program Latihan Motor Ablity}

Arie Asnaldi ${ }^{1}$, Kibadra ${ }^{2}$ 
1. Metode Pendekatan

Menyesuaikan paradigma para pelatihan karateka Dojo Angkasa Lanud maka perlu melakukan langkah-langkah berikut ini :

a. Menghubungi Pelatih Dojo Tempat Pelatihan Kecamatan Koto Tangah Kota Padang

b. Menjelaskan latar belakang dan tujuan program yang akan diterapkan

c. Memberkan motivasi kepada pelatih utama yang ada di Dojo Angkasa Lanud Padang Kecamatan Koto Tangah Kota Padang agar program ini dirasakan sebagai kebutuhan untuk mereka jalankan. Caranya dengan mengumpulkan Pelatihan-pelatih Dojo Yang ada di Kecamtan Koto Tangah tersebutKota Padang dan berdiskusi bersama.

Sejalan dengan hal tersebut, ada beberapa metode yang telah dikembangkan untuk memposisikan para pelatih yang ada. Hal ini perlu dilakukan agar mereka tidak hanya sebagai objek yang hanya pasif menerima pelatihan tetapi ikut berpartisipasi aktif untuk menjalankan program ini dan mengembangkannya agar tujuan dari program ini tercapai. Metode yang dilakukan adalah sebagai berikut: pertama pendekatan secara partisipatif dan dialogis, yaitu dengan cara menghubungi Pelatih Kepala Dojo Angkasa Lanud Kecamatan Koto Tangah terlebih dahulu.

Disini pelatih kepala akan mengubungi pelatih di setiap kelurahan, dan pelatih Kepala memberikan informasi kepada setiap pelatih-pelatih dari setiap kelurahan. Setelah itu, pelatihpelatih tersebut dikumpulkan di Dojo Angkasa Lanud Padang dan diajak bermusyawarah dengan tim pelaksana Pelatihan dari UNP. Musyawarah disini yaitu tentang Program Pelatihan yang akan dilaksanakan serta kendala-kendala yang dimungkinkan timbul dalam pelaksanaan program ini, sehingga dalam musyawarah ini bisa mendapatkan solusi akan kendala tersebut. Setelah musyawarah tersebut, kita sebagai tenaga pelaksana Pelatihan dari UNP akan mendampingi serta memberikan pelatihan kepada khalayak sasaran dalam memberikan pelatihan tersebut.

2. Metode Pelaksanaan Program

Pada metode pelaksanaan program pelatihan melalui proses pemberian materi dan Pratek lapangan dalam pencapaian tujuan pelatihan terdapat lima tahapan, yaitu:

\section{1 | Sosialisasi Program Latihan Motor Ablity}

Arie Asnaldi ${ }^{1}$, Kibadra ${ }^{2}$ 
JURNAL BERKARYA PENGABDIAN PADA MASYALTHKAS

Volume 1, No.1, 2019

ISSN-

(Print) I

Open Access / http:jba.ppj.unpracild

a. Tahap pendahuluan

Dalam tahap ini kita mempersiapkan surat izin dengan pihak terkait, mempersiapkan tempat pelatihan, mempersiapkan alat dan bahan.

b. Tahap sosilaisasi dan audiensi

Sosialisasi mengenai pelatihan realisasi motor ability ini dilakukan dengan cara mengumpulkan setiap pelatih-pelatih yang ada di Kecamatan Koto Tangah serta perwakilan setiap kelurahan di Kecamatan koto tangah. Dojo yang tergabung dalam Dojo Angkasa Lanud Padang Kecamatan koto tangah menaungi 12 Dojo yang setiap Dojo terdiri atas 15-25 orang karateka berprestasi, dan Setiap Dojo terdiri dari 1 sampai 3 pelatih yang merupakan perwakilan dari Dojo-dojo. Dalam pelaksanaan pelatihan, para peserta diberi penjelasan mengenai apa manfaat Belajar, Motorik, gerakan, keterampilan dan kemampuan motorik dan gerak bagaimana cara pemanfaatannya dalam mempermudah penyusunan bentuk-bentuk latihan, metode latihan, dan penyusunan program latihan. Masing-masing pelatih dari tiap Dojo kemudian melakukan sosialisasi lebih lanjut kepada karateka di Dojonya masingmasing. Pada akhir tahap sosialisasi lanjutan ini.

Sedangkan untuk mengatasi permasalahan dalam melakukan tes pengukuran serta evaluasi kondisi fisik bagi atlit maka diberikan solusi yaitu sebagai berikut:

1. Metode ceramah dalam penyampaian tes pengukuran dalam olahraga.

2. Metode demonstrasi untuk tes pengukuran dalam olahraga bagi pelatih.

c. Tahap pelatihan

Tempat penelitian, Penelitian ini bertempat di SMP Angkasa Lanud Padang dan Waktu penelitian ini dilaksanakan pada bulan Juni - Desember 2017.

\section{HASIL DAN PEMBAHASAN}

Program Pengabdian Masyarakat ini akan dilaksanakan di Kecamatan Koto Tangah. Kecamatan Koto Tangah merupakan salah satu Kecamatan di Kota Padang. Dari hasil wawancara dengan Dojo Angkasa Lanud di Kecamatan Koto Tangah yakni Pelatih Kepala Drs. Safwan, M.Pd diketahui bahwa di Kecamatan Koto Tangah terdapat 18 Perguruan Karate berbagai aliran perguruan.

\section{2 |Sosialisasi Program Latihan Motor Ablity} Arie Asnaldi ${ }^{1}$, Kibadra ${ }^{2}$ 
JURNAL BERKARYA PENGABDIAN PADA MASYALTHKAS

Volume 1, No.1, 2019

ISSN-

(Print) I

(Online)

Open Access / http:jba.ppj.unpracild

Di Kecamatan Koto Tangah mempunyai 4 (empat) Dojo Binaan yang dibawahi oleh Dojo

Angkasa Lanud Padang. Setiap Dojo Binaan binaan terdiri dari 25 sampai 60 orang karateka. Dojo binaan digunakan sebagai tempat pembinaan dari karateka di kelurahan yang tidak bisa datang ke Dojo Angkasa Lanud Padang pelatih yang di izin melatih selalu se izin Pelatih Kepala Sensei Saftwa.

\section{KESIMPULAN}

Kemampuan motorik merupakan modal dasar untuk keterampilan fisik yang dibutuhkan dalam kegiatan serta aktifitas olah raga bisa dipelajari dan dilatih di masa-masa awal perkembangan. Sangat penting untuk mempelajari keterampilan ini dengan suasana yang menyenangkan, tidak berkompetisi agar anak-anak mempelajari olah raga dengan senang dan merasa nyaman untuk ikut berpartisipasi.

Pada kenyataannya, tidak banyak pelatih bahkan sebagian besar pelatih yang telah di utus belum mengembangkan metode, materi dan pemahaman dalam mengembangkan materi latihannya. Sehingga di Dojo terjadi pasang surut peminat dalam mengikuti latihan. Dimana nanti dengan telah program ini diharapkan para pelatih setelah mengikuti kegiatan ini mampu menambah kasanah pengetahuan dan pemahamannya terutama dalam pengembangan keterampilan dan kemampuan motorik dan gerak kareteka.

Proses belajar gerak berbentuk kegiatan mengamati gerakan dan kemudian mencoba menirukan berulang-ulang, dan menerapkan pola -pola gerak tertentu pada situasi tertentu yang dihadapi, dan juga dalam bentuk menciptakan pola-pola gerak baru untuk tujuan-tujuan tertentu. Dalam belajar gerak karateka harus memahami gerakan untuk mampu melakukannya, maka selain unsur fisik disitu juga terlibat unsur fikir

\section{DAFTAR PUSTAKA}

Asnaldi, A. (2019). Kontribusi Motor Ability Dan Konsentrasi Terhadap Kemampuan Penguasaan Kata Heian Yodan Karateka Lemkari Dojo Angkasa Lanud Padang. Jurnal Menssana, 4(1), 17-29.

\section{3 | Sosialisasi Program Latihan Motor Ablity} Arie Asnaldi ${ }^{1}$, Kibadra ${ }^{2}$ 


\section{JURNAL BERKARYA PENGABDIAN PADA MASYALTHZSIJ \\ Volume 1, No.1, 2019 \\ ISSN \\ (Print) I \\ (Online) \\ Open Access | http:jba.ppj.unp.acild}

Kamaludin, Septian. 2015. "Hubungan motorability dengan hasilpemanjatan panjatdinding kategori rintisan (LEAD)" Universitas Pendidikan Indonesia. repository.upi.edu. perpustakaan.upi.edu

Wahid, Abdul. 2007. Shotokan Sebuah Tinjauan Alternatif Terhadap Aliran Karate-Do Terbesar di Dunia. Jakarta: PT. Raja Grafindo Persada.

74 | Sosialisasi Program Latihan Motor Ablity

Arie Asnaldi ${ }^{1}$, Kibadra ${ }^{2}$ 